\title{
The Use of In Situ X-ray Imaging Methods in the Research and Development of Magnesium-Based Grain-Refined and Nanocomposite Materials
}

DOI:

10.1007/s11837-016-2130-8

\section{Document Version}

Accepted author manuscript

Link to publication record in Manchester Research Explorer

Citation for published version (APA):

Sillekens, W. H., Casari, D., Mirihanage, W. U., Terzi, S., Mathiesen, R. H., Salvo, L., Daudin, R., Lhuissier, P., Guo, E., \& Lee, P. D. (2016). The Use of In Situ X-ray Imaging Methods in the Research and Development of Magnesium-Based Grain-Refined and Nanocomposite Materials. JOM, 68(12), 3042-3050.

https://doi.org/10.1007/s11837-016-2130-8

Published in:

JOM

\section{Citing this paper}

Please note that where the full-text provided on Manchester Research Explorer is the Author Accepted Manuscript or Proof version this may differ from the final Published version. If citing, it is advised that you check and use the publisher's definitive version.

\section{General rights}

Copyright and moral rights for the publications made accessible in the Research Explorer are retained by the authors and/or other copyright owners and it is a condition of accessing publications that users recognise and abide by the legal requirements associated with these rights.

\section{Takedown policy}

If you believe that this document breaches copyright please refer to the University of Manchester's Takedown Procedures [http://man.ac.uk/04Y6Bo] or contact uml.scholarlycommunications@manchester.ac.uk providing relevant details, so we can investigate your claim.

\section{OPEN ACCESS}




\title{
The Use of In-situ X-ray Imaging Methods in the Research and Development of Magnesium-based Grain-refined and Nanocomposite Materials
}

\author{
Sillekens W.H. ${ }^{1}$, Casari D. ${ }^{2}$, Mirihanage W.U. ${ }^{3}$, Terzi S. ${ }^{4}$, Mathiesen R.H. ${ }^{2}$, Salvo L. ${ }^{5}$, Daudin R. ${ }^{5}$, \\ Lhuissier P. ${ }^{5}$, Guo E. ${ }^{3}$, Lee P.D. ${ }^{3}$
}

\begin{abstract}
Metallurgists have an ever-increasing suite of analytical techniques at their disposition. Among these techniques are the in-situ methods, being those approaches that are designed to actually study events that occur in the material during for instance solidification, (thermo)-mechanical working or heat treatment. As such they are a powerful tool in unraveling the mechanisms behind these processes, supplementary to ex-situ methods that rather analyze the materials before and after their processing.

In this paper, case studies are presented of how in-situ imaging methods - and more specifically micro-focus X-ray radiography and synchrotron X-ray tomography - are used in the research and development of magnesium-based grain-refined and nanocomposite materials. These results are drawn from the EC collaborative research project ExoMet (www.exomet-project.eu). The first example concerns the solidification of a Mg-Nd-Gd alloy with $\mathrm{Zr}$ addition to assess the role of zirconium content and cooling rate in crystal nucleation and growth. The second example concerns the solidification of a Mg-Zn-Al alloy and its SiCcontaining nanocomposite material to reveal the influence of particle addition on microstructural development. The third example concerns the (partial) melting-solidification of Elektron21/AIN and Elektron $21 / \mathrm{Y}_{2} \mathrm{O}_{3}$ nanocomposite materials to study such effects as particle pushing/engulfment and agglomeration during repeated processing.

Such studies for one visualize and by that confirm what is known or assumed. Moreover, they advance science by monitoring and quantifying phenomena as they evolve during processing and by that contribute toward a better understanding of the physics at play.
\end{abstract}

Keywords Magnesium alloys, Solidification, Grain refinement, Nanocomposites, In situ, X-ray imaging

\footnotetext{
${ }^{1}$ European Space Agency, ESTEC - Strategic \& Emerging Technologies Team; PO Box 299, 2200 AG Noordwijk, NETHERLANDS (corresponding author: wim.sillekens@esa.int)

${ }^{2}$ NTNU Norwegian University of Science and Technology, Department of Physics; Høgskoleringen 5, 7491 Trondheim, NORWAY

${ }^{3}$ University of Manchester; Manchester M13 9PL, UNITED KINGDOM • Research Complex at Harwell; Didcot OX11 OFA, UNITED KINGDOM

${ }^{4}$ European Synchrotron Radiation Facility - Institut Laue-Langevin; EPN campus, 71 avenue des Martyrs, 38000 Grenoble Cédex, FRANCE

${ }^{5}$ Université Grenoble Alpes, Laboratoire SIMAP; 101 rue de la Physique, 38402 Saint Martin d’Hères Cédex, FRANCE
} 
Metallurgists today have a huge and growing array of tools at their disposal for analysis of the materials they are investigating and developing. Traditionally, the approach in this is to study a new material (e.g., alloy chemical composition) and/or manufacturing route (e.g., casting process) by producing samples according to certain specifications and after that characterize the resulting microstructural features and (mechanical) properties so as to identify relations between those. The analytical methods for this are thus ex situ - Latin: "away from the (original) location", or "off-site" - meaning that the synthesis and the analysis are essentially separate activities. The issue with this is that metallurgical mechanisms like crystal nucleation and growth during solidification, recrystallization and texture development during (thermo)-mechanical working, and precipitation sequences and kinetics during heat treatment are assessed on the basis of post-mortem "snap-shots". As a result, interpretations of these mechanisms are subject to assumptions and possibly ambiguity. This triggered the development of methods that rather act in situ - Latin: "in the (original) location", or "on-site" - to follow events while they occur during materials processing. These methods have emerged as very promising means supplementary to the existing ones and giving an actual insight into phenomena as they evolve during for instance casting, hot extrusion and age hardening; that is, without these phenomena being masked by those that may occur at a later stage (like phase transformations, formation of intermetallic compounds, and secondary grain growth).

While the category basically covers all methods that monitor events on the spot, this paper is limited to imaging methods and more specifically even to those methods using $X$ rays. Hard X-rays - by their short wave lengths and high photon energies versus visual light can penetrate otherwise opaque matter and are therefore used widely to image the inside of objects for medical and security applications, amongst others. This is of interest for metal solidification studies as well, as under appropriate conditions it enables to distinguish solid from liquid phases, and thus the crystals (grains) from the melt. By capturing consecutive images over time, the proceedings can thus be followed in situ and without affecting the process. The implementation of techniques designed for this purpose has been pioneered and proved successful as of late.

The results that are presented in this paper are outcomes of the ExoMet project, which is a large-scale collaborative research project that is being conducted within the 7th Framework Program of the European Commission [1]. The project (full title: "Physical processing of molten light alloys under the influence of external fields"; duration: June 2012 - July 2016; website: www.exomet-project.eu) targets high-performance aluminum- and magnesium-based materials by exploring grain-refining and nanoparticle additions in conjunction with melt treatment by electromagnetic, ultrasonic and mechanical means. These external fields are to provide for an effective and efficient dispersion of the additions in the melt and their uniform distribution in the as-cast material. The international consortium of companies, universities and research organizations integrates various disciplines as well as application areas - including automotive, aircraft, and space. Among the project partners, several are engaged in in-situ imaging investigations, of which selected examples relating to magnesium-based materials are presented below. The objective of this paper is thus to demonstrate how these methods can be used in support of the research and development of such materials. 
A common aspect in the study of grain-refined and nanocomposite materials is the presence or formation of particles in an alloy melt. These particles are to serve as inoculants for crystal nucleation, or as reinforcements of the solidified matrix, respectively. While they are typically micrometer- to nanometer-sized, their interaction with the alloy during solidification may distinctly affect microstructural development (i.e., as compared to that in the monolithic alloy). The case studies below will illustrate this point. To start off with, however, the used materials and methods are introduced.

\section{EXPERIMENTAL PROCEDURES}

\subsection{Materials}

Magnesium is being used for structural applications such as for automotive components because of its weight-saving potential (being $35 \%$ lighter than aluminum and $75 \%$ lighter than steel). Magnesium alloys are commonly applied as shape castings, using such processes as high-pressure die casting and sand casting for their manufacturing.

To study the solidification behavior with X-ray imaging methods, the contrast between the solid and liquid phases needs to be adequate. This depends on the phases' differences in chemical composition and density. As it happens, this prerequisite is met for the commercial alloy Elektron21, which is a magnesium alloy with rare-earth alloying elements. Alternatively, one may turn to model alloys that contain an alloying element that is just added to provide this contrast, such as zinc. Both options are used in the studies at hand. Ceramic particles generally provide for adequate contrast with a magnesium melt and can be imaged, provided that they are not too small.

\subsection{Methods}

For the in-situ X-ray imaging studies at hand, some distinctly different imaging principles and instruments were used.

Micro-focus X-ray radiography was employed at NTNU Norwegian University of Science and Technology. Figure 1 shows a schematic of the set-up. The laboratory-based configuration consists of a micro-focus X-ray source, a tailored Bridgman-type gradient furnace, and a dedicated X-ray detector [2]. The facility was adapted for the study of magnesium-based materials by integrating an environmentally controlled chamber to prevent self-ignition of the samples via argon insertion [3]. Samples and their holders are encased between two X-ray transparent glassy carbon plates to avoid any other reactions between molten magnesium and its surroundings. Grain buoyancy and thermo-solutal convection are minimized by orienting the sample cell horizontally; that is, with gravity acting in sample thickness direction. The operating parameters of the X-ray source can be tuned to provide the best compromise between sample transmission and absorption contrast. In a typical solidification experiment, the heating by both elements is adjusted until equi-axed nucleation occurs close to the center of the field of view (FoV), indicating a nearly isothermal condition. A spatial resolution down to $5 \mu \mathrm{m}$ can be achieved for usual imagecapturing rates of $3 \mathrm{~Hz}$. The collected data are subsequently post-processed by means of flat-fielding, noise-filtering and edge-sharpening techniques. 
Synchrotron X-ray tomography was employed at Diamond Light Source, UK Facility, France (beamline ID19). Figure 2 shows a schematic of the set-up at the latter site. The sample is contained in an argon-filled quartz capillary (to avoid reaction with oxygen and by that self-ignition of the sample), which is fixed on an alumina rod and mounted on a rotating stage. An induction coil is used to heat the samples; the temperature is monitored through a pyrometer and controlled by manually adjusting power supply to the electric generator. The high brilliance of the $\mathrm{X}$-ray source allows for very fast imaging. Thus, numerous projections are recorded by the detector system as the stage rotates, from which afterwards 3D images can be reconstructed by numerical treatment. Details of the two employed tomography set-ups differ somewhat, as is specified in the concerned subsections below.

Associated with the differences in the used imaging principles and instruments, there are also differences in the capabilities of the two methods [4]. Where micro-focus X-ray radiography can be implemented as a stand-alone facility and be based for most on commercially available X-ray sources and other components, synchrotron X-ray tomography requires access to one of the few dedicated large-scale facilities. As the names further suggest, radiography provides projections (2D) and tomography provides spatial information (3D).

\section{CASE STUDIES}

\subsection{Solidification of a $\mathrm{Mg}-\mathrm{Nd}-\mathrm{Gd}$ alloy with $\mathrm{Zr}$ addition}

An important class of magnesium alloys uses rare-earth alloying elements for the purpose of enhancing mechanical properties and notably creep resistance. For these alloys, zirconium is commonly added up to saturation level as a potent grain refiner, meaning that it promotes grain nucleation upon solidification which then leads to a correspondingly finer and more favorable microstructure.

The solidification experiments that are reported here were designed to study the grain-refinement mechanism induced by the presence of zirconium in these alloys. Microfocus $\mathrm{X}$-ray radiography was used as it enables multiple experiments to be done to explore the influence of such parameters as cooling rate and with still sufficient spatiotemporal resolution to distinguish the main morphological features. Two alloy variants based on the Elektron21 alloy were employed (chemical composition 2.8 wt.\% Nd, 1.5 wt.\% Gd, balance $\mathrm{Mg}$, which is in line with the commercial equivalent except for the addition of $\mathrm{Zn}$ ). $\mathrm{Zr}$ was added in unsaturated and supersaturated concentrations of 0.35 wt.\% and 0.86 wt.\%, respectively. For these experiments at NTNU Norwegian University of Science and Technology, samples were prepared by sectioning $50 \times 5 \times 1 \mathrm{~mm}$ strips from the as-cast ingots, and manually grind them with progressively finer silicon carbide paper (up to 4000 grit) to reach final dimensions of $50 \times 5 \times 0.20(1) \mathrm{mm}$.

Figure 3 shows the effect of zirconium addition level on the development of the $\alpha-\mathrm{Mg}$ grains for a relatively low cooling rate. As time proceeds - and temperature drops - the grains that appear in bright contrast are growing with a typical six-fold symmetry associated with the hexagonal closed-packed crystal lattice of magnesium. In the alloy with high $\mathrm{Zr}$ content, the number of nucleation events is 1.5-2 times higher than in the alloy with low $\mathrm{Zr}$ 
content. Upon closer examination of the images for the supersaturated alloy, one also detects several dark spots in the melt just ahead of the solid/liquid interface. These could be either pre-existing zirconium particles pushed by the growing grains, or new particles forming through a secondary peritectic reaction in the enriched liquid between neighboring grains. Interestingly - despite being several micrometers in size - these particles appear not to promote any further nucleation and are eventually trapped in the eutectic regions between $\alpha-M g$ grains.

For further comparison, average grain size $d$ after solidification has been estimated as:

$$
d=\left(\frac{6}{\pi N_{0}}\right)^{1 / 3},
$$

where $N_{0}$ is the grain density; i.e., the number of counted grains divided by the FoV volume $\left(\sim 1.11 \mathrm{~mm}^{3}\right)$. For the alloy with low $\mathrm{Zr}$ content, resulting values are 370,245 and $200 \mu \mathrm{m}$ for imposed cooling rates of $0.0125,0.05$ and $0.1 \mathrm{~K} / \mathrm{s}$, respectively. For the alloy with high $\mathrm{Zr}$ content, the matching values are 290, 210 and $170 \mu \mathrm{m}$. This confirms that a higher zirconium addition level indeed enhances grain refinement, as well as that a higher cooling rate leads to finer grains. The last-mentioned grain-size value in this set appears to be in fair agreement with earlier grain-refinement efficiency tests using a Mg-Nd-Zn alloy [5]. Further, it is to be noted that grain-size dependence on cooling rate is more pronounced for the alloy with the low grain-refiner addition level, similar to results reported earlier for alloys based on the AlCu system [6].

Finally, solid-area fraction data from these experiments are presented in Figure 4. For a given cooling rate, the alloy with high $\mathrm{Zr}$ content generally exhibits a higher rate of solid formation than the alloy with low $\mathrm{Zr}$ content, which then results in a generally higher solidarea fraction. For the higher cooling rates, solidification sets in at higher undercooling, suggesting the presence of a higher number of $\mathrm{Zr}$ particles becoming potent only if a sufficiently high undercooling is reached. This is in accordance with the so-called FreeGrowth model [7]. A subsequent decrease in the rate of solid formation is noted for the alloys solidifying at 0.05 and $0.1 \mathrm{~K} / \mathrm{s}$, occurring almost at a same undercooling of $\sim 1.25 \mathrm{~K}$ and $\sim 1.5 \mathrm{~K}$, respectively: no further grain nucleation is observed in the images at these stages. The alloy with high $\mathrm{Zr}$ content solidifying at $0.0125 \mathrm{~K} / \mathrm{s}$ behaves similarly, tilting at $\sim 0.7 \mathrm{~K}$. In contrast, the curve for the alloy with low $\mathrm{Zr}$ content at this cooling rate evolves almost linearly, which can be interpreted as near-equilibrium solidification.

\subsection{Solidification of a Mg-Zn-Al alloy and its SiC-containing nanocomposite material}

One of the main challenges in the melt-metallurgical synthesis of nanocomposites is in achieving a uniform distribution of the particles in the as-cast material. This relates to the introduction of the particles in the melt, but also to the interaction between particles and the solid-liquid interface during solidification. As for the latter, the presence of particles may also affect the morphology of the growing grains.

The solidification experiments that are reported here were designed to study the effects of nanoparticles on the primary dendritic microstructural evolution. Synchrotron Xray tomography was used as it enables to capture moving solid-liquid interfaces through reasonably good phase contrast. Material was prepared by blending magnesium alloy AZ91 with pure zinc so as to obtain a model alloy of specific chemical composition ( $25 \mathrm{wt} . \% \mathrm{Zn}, 7$ wt.\% Al, balance $\mathrm{Mg}$ ). Nanocomposite samples were then synthesized by adding $0.7 \mathrm{wt} . \% \mathrm{SiC}$ 
powder (average particle size $\sim 25 \mathrm{~nm}$ ) applying ultrasound to the melt before casting to enhance particle dispersion. For these experiments at Diamond Light Source, $\varnothing 1.2 \mathrm{~mm}$ cylindrical samples are extracted from the ingots and then encapsulated by graphite and quartz tubes.

Figure 5 shows results for the solidification of the monolithic alloy (top) and the composite material (bottom). These 2D transverse slices were constructed from the 3D tomographic images obtained at distinct points in time, and thus at distinct points during solidification. The cooling rate was set to be quite low to get low growth rates and by that enhance image quality (solid-liquid movement during the acquisition of a single tomographic image may induce image blurring). It is to be noted that individual particles as well as actual crystal nucleation cannot be recognized due to the limited spatiotemporal resolution. Further, grains below some micrometers of size will be beyond detection as for the limited absorption difference. The slices at the far left of the figure are those for which first signs of dendrites are observed; these emerge in dark contrast. Upon comparing the chronological images, it appears that the composite material shows enhanced nucleation and reduced growth rate versus the monolithic alloy. Smaller average grain size results after solidification: $235 \pm 35 \mu \mathrm{m}$ for the alloy with particles as compared to $300 \pm 50 \mu \mathrm{m}$ for the one without particles. From literature it is known that the $\alpha-M g$ growth pattern can be remarkably influenced by the characteristics of the surrounding melt [8]. That submicron-sized particles in a solidifying melt can either be engulfed or pushed by the moving solidification front is also recognized. Due to their generally poor wettability by a metal melt and their large surface-to-volume ratio, uniform dispersion of nanoparticles is challenging. Clustering is commonly observed and tried to be countered by melt-processing methods such as ultrasonic treatment [9-11]. From this it seems reasonable that particle pushing during primary dendritic phase solidification needs to be assumed for the experiments at hand. Earlier work also suggests that phase growth can be affected by nanoparticle self-assembly ahead of the solidification front $[12,13]$. Such accumulation can act as a barrier to diffuse solute (rejected at the solid-liquid interface) away from the advancing solidification front, introducing higher local enrichment close to the solid-liquid interface as compared to regular solidification conditions. That in turn can retard phase growth. Also, lower solute enrichment in the bulk liquid caused by higher local enrichment close to the solid-liquid interface can permit higher undercooling, increasing nucleation potential. Both mechanisms may lead to microstructural refinement, as observed in the current experiments.

\subsection{Melting-solidification of Elektron21/AIN and Elektron21/ $\mathrm{Y}_{2} \mathrm{O}_{3}$ nanocomposite materials}

Interactions between particles and the melt upon solidification can apparently affect grain morphology (as discussed in the previous case study), but may also lead to non-uniform particle distributions in the as-cast material such as particle clusters on the grain boundaries. This also poses the question how these interactions extend and affect eventual material quality when multiple melting and solidification steps are involved, like in recycling.

The (partial) melting and subsequent solidification experiments that are reported here were designed to study the evolution of particle distribution as well as to detect and observe any reactions of particles with the melt. As yet, most of the experimental data available on these issues are based on post-mortem observations of quenched samples [1417], or on in-situ 2D experiments performed using transparent organic alloys [18-20]. 
Synchrotron X-ray tomography was used here as it enables 3D real-time observation with actual metallic alloys, thus avoiding potential bias introduced by the experimental limitations in these earlier studies. Two metal-matrix nanocomposite materials were employed, both based on the Elektron21 alloy. To the base alloy (chemical composition $2.8 \mathrm{wt} . \% \mathrm{Nd}, 1.2$ wt.\% Gd, 0.3 wt.\% Zn, 0.4 wt.\% Zr, balance Mg), either 1 wt.\% AIN (average particle size 20$30 \mathrm{~nm}$ ) or $1 \mathrm{wt} . \% \mathrm{Y}_{2} \mathrm{O}_{3}$ (average particle size $\sim 500 \mathrm{~nm}$ ) were added, applying ultrasound to the melt before casting to enhance particle dispersion [21]. For these experiments at the European Synchrotron Radiation Facility, $\varnothing 1 \times 5 \mathrm{~mm}$ cylindrical samples were machined from the as-received ingot and encapsulated by a quartz tube under argon atmosphere.

Figure 6 presents results obtained from a partial melting experiment on an Elektron21/AIN sample. Images (a) and (b) are 2D transverse slices extracted from the 3D tomographic images in the solid and the partially molten state, respectively. In (a), the rareearth rich eutectic appears in bright contrast while the $\alpha$-Mg grains appear in dark contrast. Upon reaching the eutectic temperature, the intermetallic phases located in the interdendritic regions start melting. In (b), temperature has further increased, revealing that the $\alpha-\mathrm{Mg}$ phase coarsens and its initial dendritic morphology becomes more globular. Simultaneously the solid fraction has decreased and the contrast of the liquid phase has become less bright. Further, it appears that some liquid droplets nucleate and grow inside the grains, which follows a mechanism discussed elsewhere [23]. Moreover, bright white spots emerge as is obvious from (c), which is a larger magnification of the sample at the same temperature. Metallography has revealed that in this composite material the AIN particles are coated by a Zr-rich layer [21], possibly ZrN [24, 25], and mainly appear as micrometer-sized clusters. In some cases, this layer grows into a larger phase, also rich in heavy elements but with a possibly different structure and composition. It is therefore believed that the observed bright white spots are small clusters of AIN particles coated by a Zr-rich layer and possibly embedded in a third phase that has grown from the particle surface. The heavy elements in these heterogeneous and compact clusters then act as markers, revealing the presence of the actual AIN particles. From the image it is clear that the particles/clusters are located at the solid-liquid interface as well as within the $\alpha-\mathrm{Mg}$ phase. While it cannot be ruled out that the particles moved from the former to the latter during melting, this is nevertheless a strong indication that these particles have been there in the as-received state and thus have been engulfed upon initial solidification. The Zr-rich layer on the AIN particles may be instrumental in creating a favorable interface condition for such engulfment. Finally, (d) shows a 3D rendering of the particle distribution in the partially molten state, being indicative for the efficiency of the original dispersion process. The distribution seems fairly uniform at the sample scale, with most particles appearing as micrometer-sized heterogeneous clusters containing heavy elements. As particles in a melt tend to agglomerate in the absence of stirring, it appears likely that particle distribution in the as-received sample has been even more uniform than after its partial re-melting.

Figure 7 shows results from the same experiment during its successive resolidification stage. Clearly the bright phase forming from the AIN particle surface grows when it gets in contact with the liquid phase, which is locally enriched in solute. The exact structure and composition of this growing phase is still to be determined. Nevertheless, it is apparent that additional complexity is introduced to the exploration of (nano)-composite materials as particles may be reacting with the melt during their processing.

Figure 8 presents results obtained from a full melting and subsequent solidification experiment on an Elektron $21 / \mathrm{Y}_{2} \mathrm{O}_{3}$ sample, showing $2 \mathrm{D}$ longitudinal slices (top) and the 
corresponding 3D renderings of the particles (bottom) at successive time steps. This particular composite system has proven to be stable; i.e., the ceramic particles do not react in contact with the magnesium-alloy melt. After completely melting the matrix (images at the far left of the figure), most of the particles have settled at the bottom of the sample. Yet, some large clusters ended up at the sample wall (its oxide skin appears bright in these images), so that their interaction with the solidification front during cooling could be observed. During cooling a thermal gradient was present with solidification progressing from the bottom of the sample to the top. It appears that some particles are pushed away from the sample wall as the solidification front passes. The observation of large particle clusters being pushed by growing dendrites was recently reported for an aluminum-based nanocomposite material [26]. Here, particle clusters remained in the re-molten state as stable branched networks (coinciding with the original grain boundaries) that turned out to be difficult to break up. In the present case, however, pushing goes along with cluster fragmentation and some particles are transported far from their original location at the sample wall. Further analyses and additional tests are ongoing to shed light on the mechanisms involved.

\section{CONCLUSION AND OUTLOOK}

In this paper it is shown that in-situ imaging methods such as micro-focus X-ray radiography and synchrotron X-ray tomography can be used to study microstructural features of magnesium-based grain-refined and nanocomposite materials and local mechanisms involved during their melt-metallurgical processing.

Results for one visualize and by that confirm what is known or assumed. Examples are that magnesium crystals upon solidification grow in a six-fold symmetry, that higher cooling rates during solidification lead to finer microstructures, and that zirconium is a potent grain refiner in magnesium rare-earth alloys. Moreover, they provide for additional insight by enabling to monitor and quantify phenomena and by that contribute toward a better understanding of the physics at play. Examples are that nanoparticles despite their size can affect the morphology of the growing grains during solidification, that engulfment and/or pushing of particles by the solidification front may or may not occur depending on the specifics of the system, and that chemical reaction at the solidification front may induce the formation of new particles. While the former serves the general understanding and can be used for educational purposes, the latter is an enabler for enhancing scientific understanding and supporting technological development to be of eventual benefit for industrial applications.

There are restrictions in the use of these methods nevertheless. The number of synchrotron facilities is limited, so access is a concern along with the need for specific expertise, the long lead times and the limited operational flexibility of the experimental campaigns. Further, concessions may have to be done on alloy compositions (regarding the necessary contrast) and the design of experiments (e.g., at the expense of duplication trials). Nowadays tomography imaging detectors (cameras) with very high acquisition rates are used, leading to huge amounts of collected data, while for other techniques such as diffraction the increasing use of 2D detectors poses a similar challenge. Thus there is an extensive effort to be made on the storage, transfer, processing and analysis of these data. Data management in practice is one of the main concerns, especially in regard of non-expert 
users. For solidification studies, there still are technical constraints such as on the attainable resolution and field of view of the images versus the features to be studied, and in setting experimental conditions possibly close to those in practice. The former would imply a smaller beam and/or better optics and wider detectors. The latter would imply larger sample volumes and faster cooling rates, meaning higher energies and higher acquisition frequencies (i.e., higher photon fluxes), respectively. Developments like these are indeed being considered in topical upgrading programs at existing facilities including the European Synchrotron Radiation Facility. Recapitulating, for the foreseeable future it is not expected that especially synchrotron studies will become more economical, but faster and more accurate and only better accessible if post-processing becomes easier. They thus remain to be regarded as high-gain techniques supplementary to those in the metallographical laboratory. In the laboratory, in-situ studies will become more common as capabilities of laboratory tomography systems, small-angle X-ray scattering devices and so on further evolve. Moreover, the more "conventional" ex-situ characterization techniques remain crucial in their own right, yet also for the preparation and evaluation of in-situ studies.

\section{ACKNOWLEDGEMENTS}

The authors wish to acknowledge financial support from the ExoMet project, which is cofunded by the European Commission in the 7th Framework Program (contract FP7-NMP3LA-2012-280421), by the European Space Agency and by the individual partner organizations. Among the consortium, Helmholtz-Zentrum Geesthacht (MagIC), Germany, is thanked for the provision of the magnesium rare-earth testing materials.

Diamond Light Source - Research Complex at Harwell, United Kingdom, is acknowledged for the use of the Diamond-Manchester branch-line under experiment MT11837-1 and the support from the 113 team. The European Synchrotron Radiation Facility, France, is acknowledged for the allocation of beam-time in the framework of the proposals MA-2984 and LTP MA1876 and the strong support by the ID19 beamline team.

\section{REFERENCES}

1. W.H. Sillekens, D.J. Jarvis, A. Vorozhtsov, V. Bojarevics, C.F. Badini, M. Pavese, S. Terzi, L. Salvo, L. Katsarou, and H. Dieringa, Metall. Mater. Trans. A, 45A, 3349 (2014).

2. A.G. Murphy, D.J. Browne, W.U. Mirihanage, and R.H. Mathiesen, Acta Mater., 61, 4559 (2013).

3. D. Casari, W.U. Mirihanage, K.V. Falch, I.G. Ringdalen, J. Friis, R. Schmid-Fetzer, D. Zhao, Y. Li, W.H. Sillekens, and R.H. Mathiesen, Acta Mater., 116177 (2016).

4. C. Rakete, C. Baumbach, A. Goldschmidt, D. Samberg, C.G. Schroer, F. Breede, C. Stenzel, G. Zimmermann, C. Pickmann, Y. Houltz, C. Lockowandt, O. Svenonius, P. Wiklund, and R.H. Mathiesen, Rev. Sci. Instrum., 82, 105108 (2011).

5. C. Wang, M. Sun, F. Zheng, L. Peng, and W. Ding, J. Magnesium and Alloys, 2, 239 (2014).

6. A.G. Murphy, W.U. Mirihanage, D.J. Browne, and R.H. Mathiesen, Acta Mater., 95, 83 (2015). 
7. A.L. Greer, A.M. Bunn, A. Tronche, P.V. Evans, and D.J. Bristow, Acta Mater., 48, 2823 (2000).

8. M.Y. Wang, Y.J. Xu, T. Jing, G.Y. Peng, Y.N. Fu, and N. Chawla, Scripta Mat., 67, 629 (2012).

9. R. Casati, Aluminum Matrix Composites Reinforced with Alumina Nanoparticles, 1st ed. (Springer, 2016), pp. 9-15, 27-28, 59-72.

10. X. Li, Y. Yang, and X. Cheng, J. Mater. Sci., 39, 3211 (2004).

11. W. Mirihanage, W. Xu, J. Tamayo-Ariztondo, D. Eskin, M. Garcia-Fernandez, P. Srirangam, and P. Lee, Mater. Lett., 164, 484 (2016).

12. L. Chen, J. Xu, H. Choi, H. Konishi, S. Jin, and X. Li, Nat. Commun., 5, 3879 (2014).

13. L. Chen, J. Xu, and X. Li, Mater. Res. Lett., 3, 43 (2015).

14. F.R. Juretzko, D.M. Stefanescu, B.K. Dhindaw, S. Sen, and P.A. Curreri, Metall. Mater. Trans. A, 29, 1691 (1998).

15. Y.M. Youssef, R.J. Dashwood, and P.D. Lee, Compos. Part. A: Appl. Sci. Manuf., 36, 747 (2005).

16. T. Lierfeld, P. Gandham, M. Kolbe, T. Schenk, H.M. Singer, G. Eggeler, and D.M. Herlach, Mater. Sci. Eng. A, 449-451, 689 (2007).

17. D.M. Stefanescu, B.K. Dhindaw, S.A. Kacar, and A. Moitra, Metall. Trans. A, 19, 2847 (1988).

18. D.R. Uhlmann, B. Chalmers, and K.A. Jackson, J. Appl. Phys., 35, 2986 (1964).

19. J.A. Sekhar and R. Trivedi, Mater. Sci. Eng. A, 147, 9 (1991).

20. D.M. Stefanescu, F.R. Juretzko, A. Catalina, B.K. Dhindaw, S. Sen, and P.A. Curreri, Metall. Mater. Trans. A, 29, 1697 (1998).

21. L. Katsarou, M. Mounib, W. Lefebvre, S. Vorozhtsov, M. Pavese, C. Badini, J.M. MolinaAldareguia, C.C. Jimenez, M.T. Pérez Prado, and H. Dieringa, Mater. Sci. Eng. A, 659, 84 (2016).

22. D. Paganin, S.C. Mayo, T.E. Gureyev, P.R. Miller, and S.W. Wilkins, J. Microsc., 206, 33 (2002).

23. S. Terzi, L. Salvo, M. Suéry, A.K. Dahle, and E. Boller, J. Mater. Sci., 48, 7422 (2013).

24. A. Koltsov, F. Hodaj, N. Eustathopoulos, A. Dezellus, and P. Plaindoux, Scr. Mater., 48, 351 (2003).

25. R.E. Loehman and A.P. Tomsia, Acta Metall. Mater., 40, S75 (1992).

26. R. Daudin, S. Terzi, P. Lhuissier, L. Salvo, and E. Boller, Mater. Des., 87, 313 (2015). 


\section{FIGURE CAPTIONS}

Figure 1 Micro-focus X-ray radiography: experimental set-up in the NTNU home-lab (Viscom Vision Technology XT9100 X-ray source, (1) sample, (2) heater element, (3) adiabatic zone, (4) field of view, (5) projected image, (6) Vosskuhler DXI11000 CCD camera equipped with a Scint-X scintillator).

Figure 2 Synchrotron X-ray tomography: experimental set-up on the ESRF-ID19 beamline (1) sample, (2) quartz capillary, (3) alumina rod, (4) rotation stage, (5) induction coil, (6) pyrometer, (7) scintillator, (8) optics system, (9) PCO Dimax camera).

Figure 3 Microstructural evolution during solidification of Elektron21-based alloys with different zirconium contents $C_{Z r}$ - cooling rate $C R=0.0125 \mathrm{~K} / \mathrm{s}$ (experimental: thermal cycling with cooling from $943 \mathrm{~K}$; imaging: micro-focus $\mathrm{X}$-ray radiography, beam energy $40 \mathrm{keV}$ and $50 \mu \mathrm{A}$, field of view $2,817 \times 1,848 \mu \mathrm{m}$, virtual pixel size $\sim 1.4 \mu \mathrm{m}$, image-capturing rate $1 \mathrm{~Hz}$ ).

Figure 4 Solid-area fraction in dependence on the undercooling $\Delta T$ during solidification of Elektron21-based alloys with different zirconium contents $C_{Z r}$ and for different cooling rates $C R$ (experimental and imaging: as for Figure 3, with solid grain envelopes measured using a manual grey-level thresholding of the images).

Figure 5 Microstructural evolution during solidification of a Mg-25Zn-7Al alloy and a Mg$25 \mathrm{Zn}-7 \mathrm{Al} / \mathrm{SiC}$ nanocomposite material - from left to right: at $635 \mathrm{~K}$, at $622 \mathrm{~K}$, at $604 \mathrm{~K}$, at $577 \mathrm{~K}$, and at $532 \mathrm{~K}$ (experimental: cooling from $\sim 665 \mathrm{~K}$ at $0.05 \mathrm{~K} / \mathrm{s}$; imaging: synchrotron $\mathrm{X}$-ray tomography, polychromatic beam, beam energy 8-30 $\mathrm{keV}, 1200$ projections over $180^{\circ}$ rotation per tomographic image, exposure time $10 \mathrm{~ms} /$ projection, distance sample-scintillator $\sim 10 \mathrm{~cm}, 1.6 \mu \mathrm{m}$ effective spatial resolution with a $1280 \times 1080$ pixel imaging array).

Figure 6 Microstructural evolution during melting of an Elektron21/AIN nanocomposite material: (a) as-received state at $293 \mathrm{~K},(\mathrm{~b}-\mathrm{d})$ semi-solid state at $875 \mathrm{~K}$ (experimental: heating at $0.1 \mathrm{~K} / \mathrm{s}$; imaging: synchrotron X-ray tomography, beam energy $9.6 \mathrm{keV}, 800$ projections over $180^{\circ}$ rotation, time scan $\sim 1 \mathrm{~s}$, field of view $816 \times 816 \times 406$ voxels, voxel size $1.1 \mu \mathrm{m}$, Paganin 3D image reconstruction [22]).

Figure 7 Particle reaction during solidification of an Elektron21/AIN nanocomposite material: (a) at $873 \mathrm{~K},(\mathrm{~b})$ at $863 \mathrm{~K},(\mathrm{c})$ at $841 \mathrm{~K},(\mathrm{~d})$ at $806 \mathrm{~K}$, and (e) solidified state, including a $3 D$ rendering of the phase morphology (experimental: partial melting, then cooling from $878 \mathrm{~K}$ at $0.1 \mathrm{~K} / \mathrm{s}$; imaging: as for Figure 6).

Figure 8 Pushing and fragmentation of particle clusters during solidification of an Elektron21/ $\mathrm{Y}_{2} \mathrm{O}_{3}$ nanocomposite material (experimental: cooling from liquid state at $1 \mathrm{~K} / \mathrm{s}$; imaging: synchrotron X-ray tomography, beam energy $9.6 \mathrm{keV}, 800$ projections over $180^{\circ}$ rotation, time scan $\sim 3 \mathrm{~s}$, field of view $816 \times 816 \times 816$ voxels, voxel size $1.1 \mu \mathrm{m}$, Paganin 3D image reconstruction). 


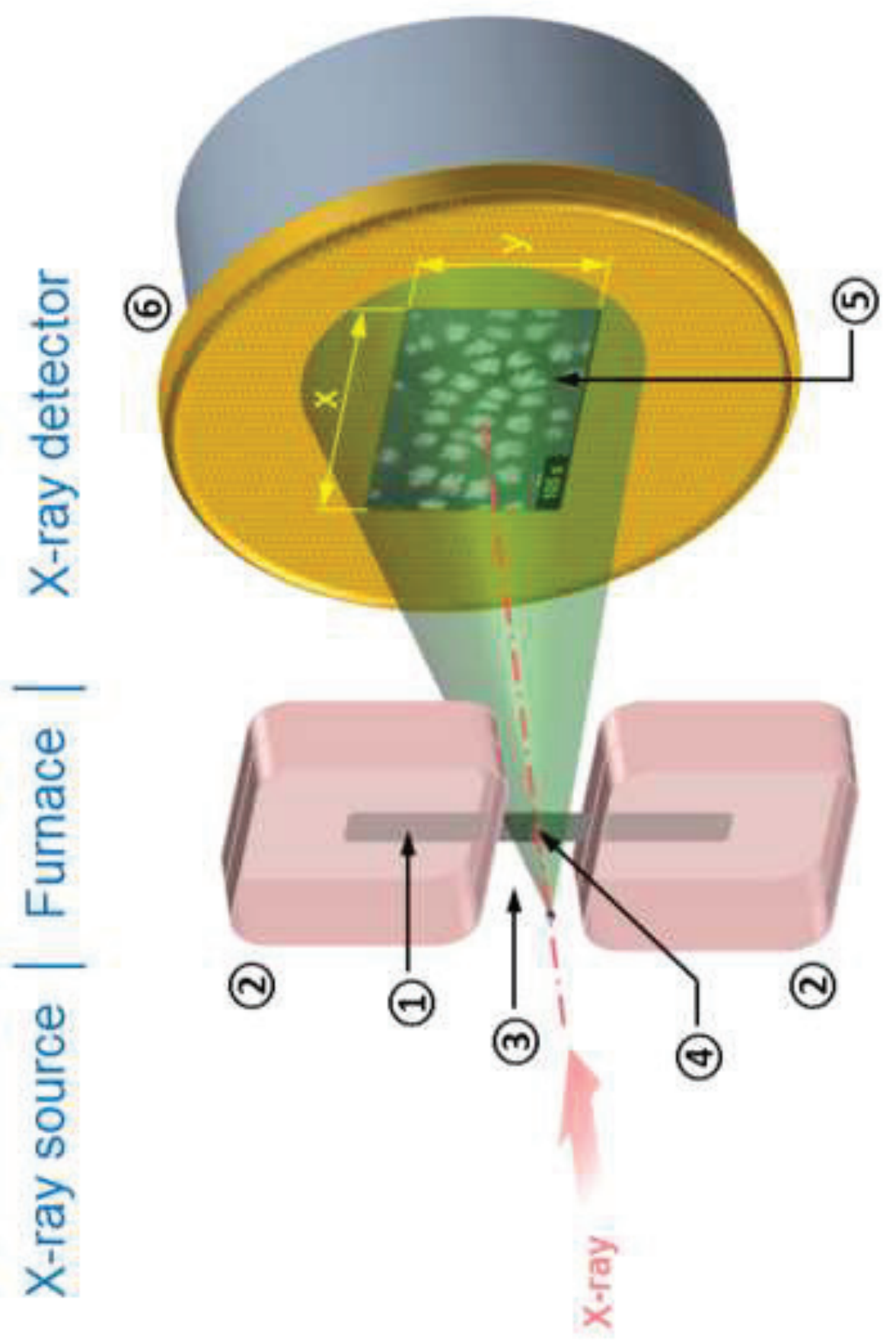

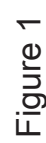



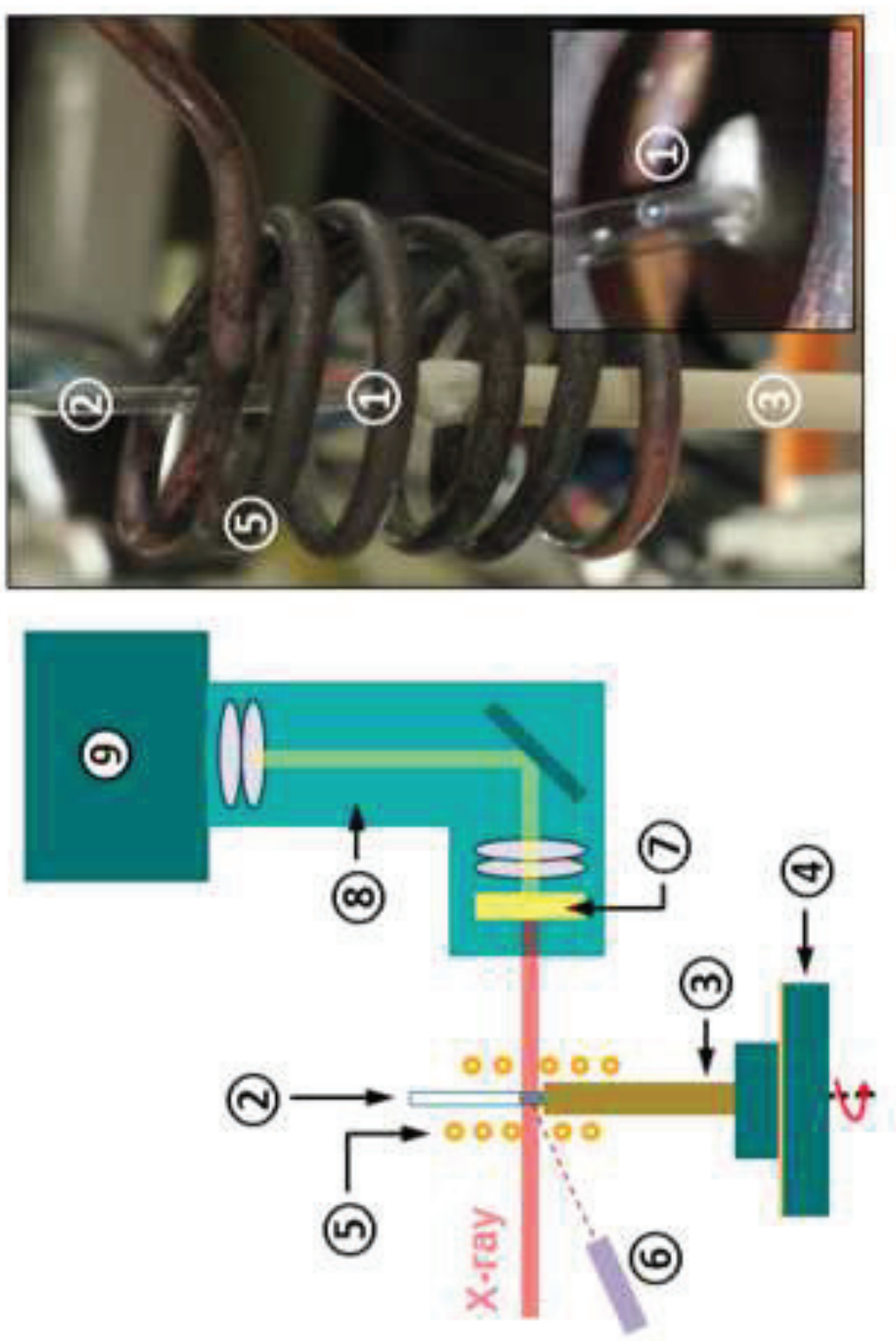

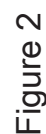



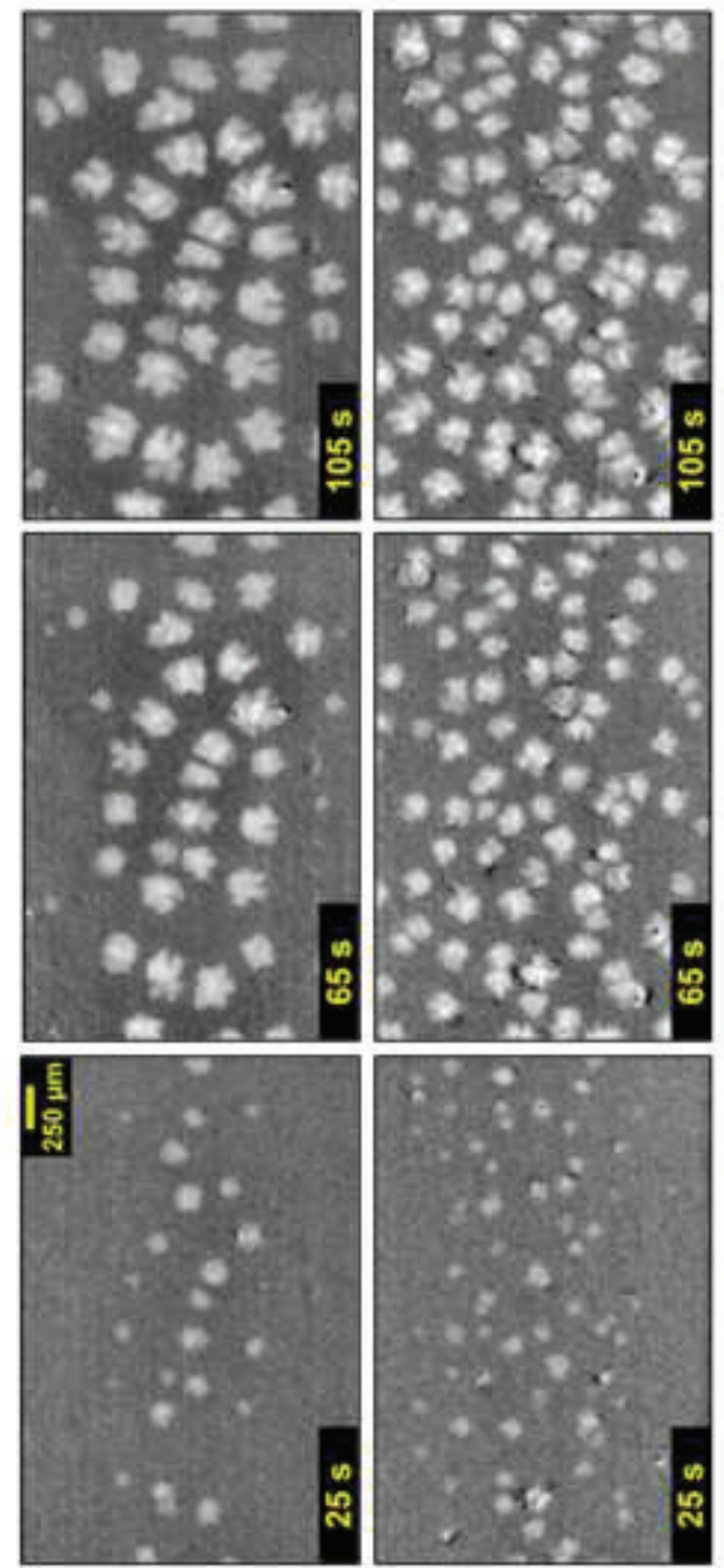

$\%$.

$\% 8^{\circ} \mathrm{M} 98^{\circ} \mathrm{x}$ 


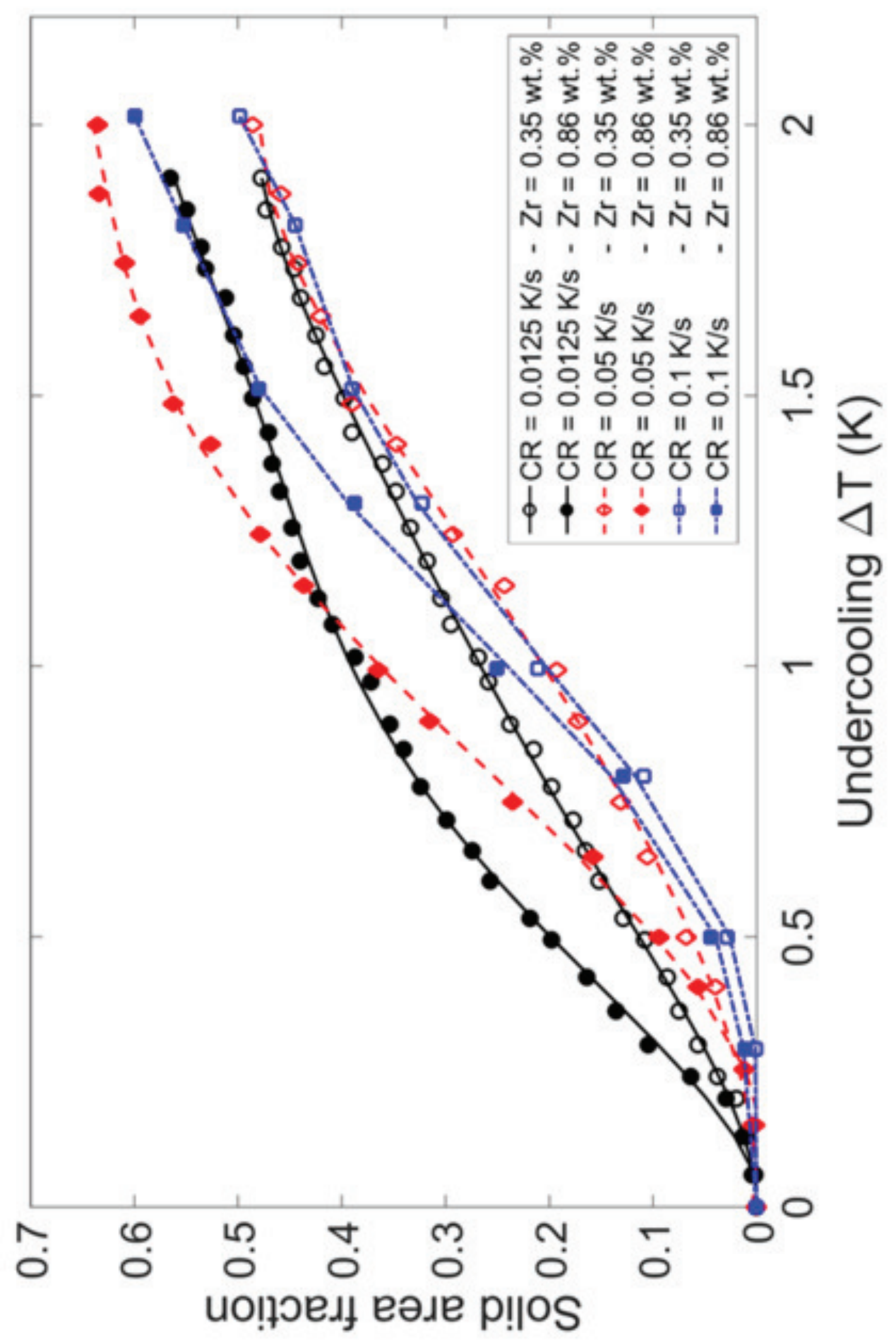



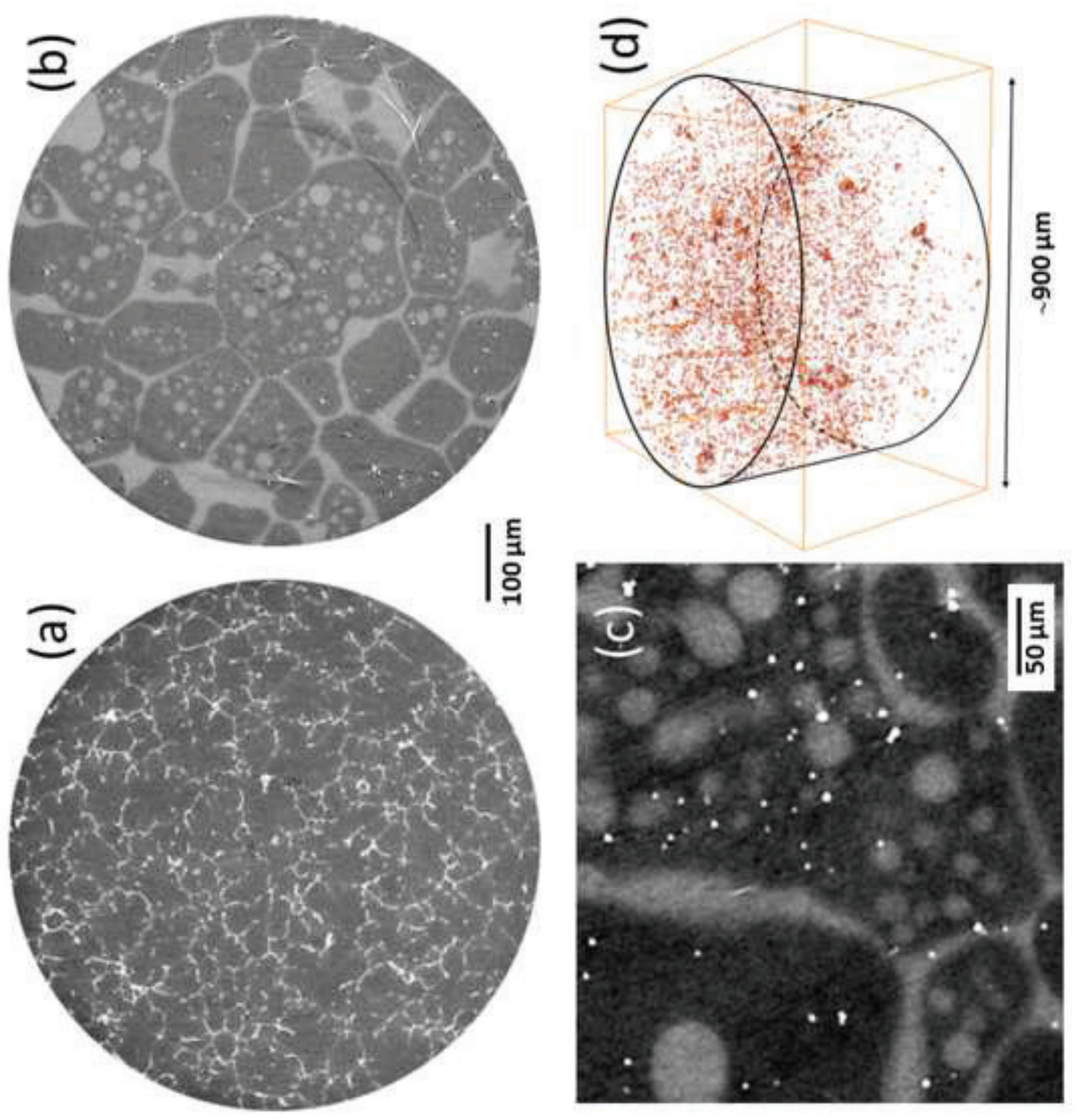


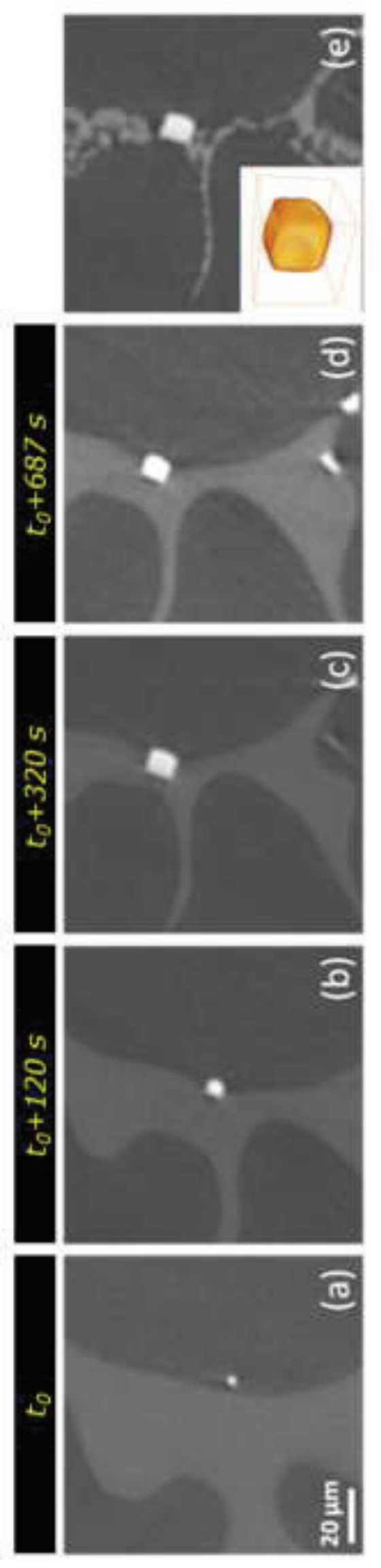

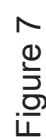




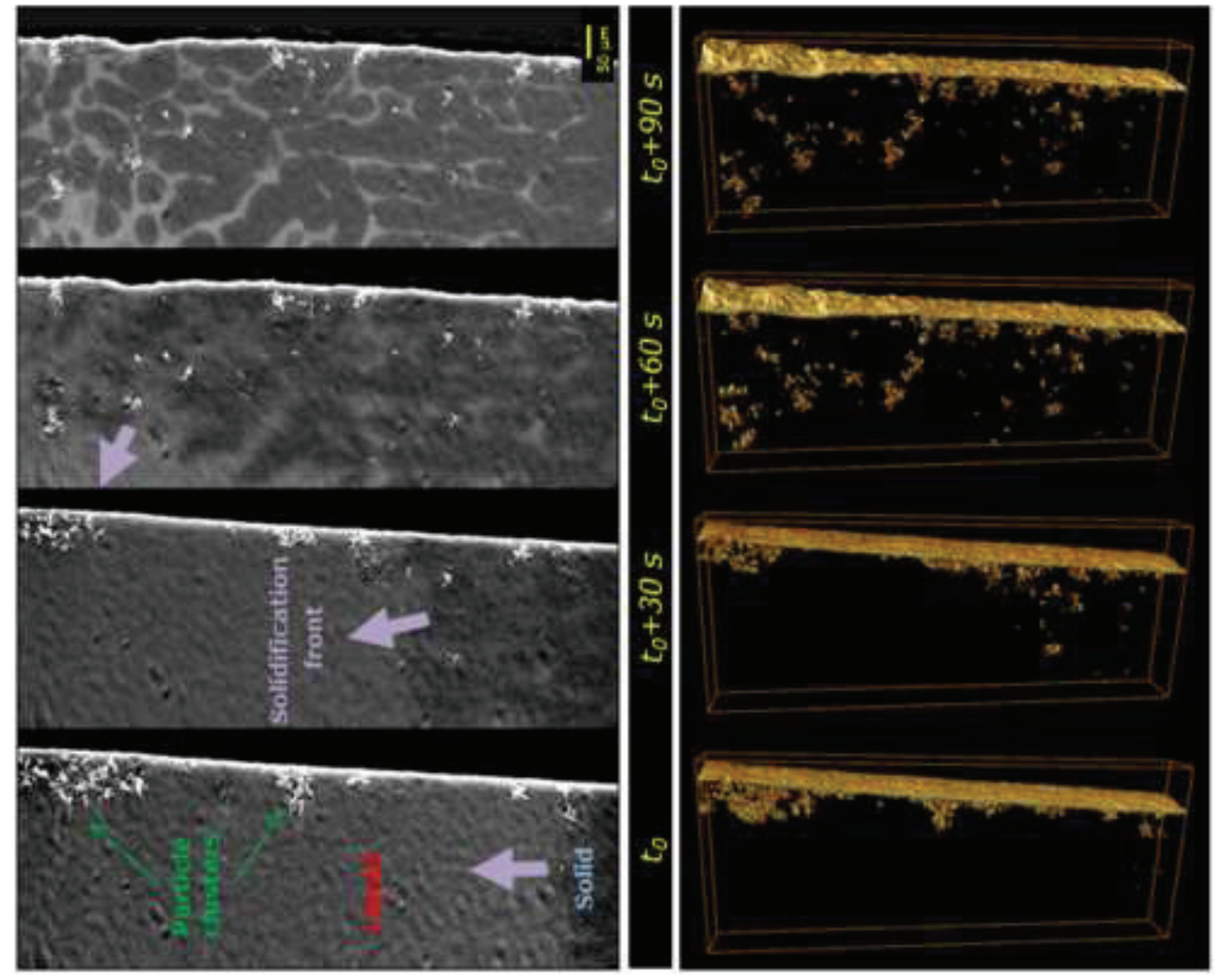

$\infty$
0
$\frac{0}{5}$
믄 